\title{
Maintenance of the Adh polymorphism in Ambystoma tigrinum nebulosum (tiger salamanders). I. Genotypic differences in time to metamorphosis in extreme oxygen environments
}

\author{
PATRICK A. CARTER* \\ Department of Environmental, Population and Organismic Biology, Campus Box 334, University of Colorado, \\ Boulder, CO 80309 and Rocky Mountain Biological Laboratory, PO Box 519, Crested Butte, CO 81224, U.S.A.
}

\begin{abstract}
Populations of gilled tiger salamanders (Ambystoma tigrinum nebulosum) living in ephemeral ponds were studied in order to determine what evolutionary processes might be affecting genetic variation at the alcohol dehydrogenase $(A d h)$ locus. Ponds frequently dried in late summer; salamanders that did not metamorphose and leave drying ponds died of desiccation. Low levels of water oxygen significantly slowed metamorphosis of tiger salamanders in both natural and laboratory populations. $A d h-S S$ frequency was significantly positively correlated with daily oxygen maxima in ponds, $A d h-F F$ frequency demonstrated a nonsignificant trend to be negatively correlated with this measure, and $A d h-S F$ frequency was unrelated to pond oxygen. Genotype frequency changes across the season in hypoxic and supersaturated ponds suggested that differential mortality of genotypes might explain the relationships with pond oxygen, although other mechanisms cannot be ruled out. Individuals of the Adh-SS genotype metamorphosed more slowly in hypoxic water than in normoxic water in the laboratory, and $A d h-F F$ individuals metamorphosed more slowly in supersaturated water in the field, and in hypoxic water in the laboratory, than they did in normoxic water. $A d h-S F$ individuals metamorphosed at the same rate in all oxygen environments. These data suggest that the $A d h$ polymorphism in tiger salamanders is being maintained by selection for $A d h$ or for a linked locus through differential metamorphosis in extreme oxygen environments.
\end{abstract}

Keywords: alcohol dehydrogenase, allozymes, Ambystoma tigrinum, drift, hypoxia, selection.

\section{Introduction}

Evolutionary biologists study protein variation for at least two general reasons. First, examining naturally occurring genetic variants is one of several good ways of investigating evolutionary processes (Gillespie, 1991; Garland \& Carter, 1994). Secondly, small changes in the amino acid composition of an enzyme can have large functional effects (Graves \& Somero, 1982; Somero, 1995); thus, naturally occurring enzyme variants (e.g. allozymes) are a unique tool with which to investigate the evolution of specific

\footnotetext{
*Present address: Department of Zoology, Washington State University, Pullman, WA 99164-4236, U.S.A. E-mail: pacarter@wsu.edu
}

enzymes and the metabolic pathways in which they occur (Hochachka \& Somero, 1984). Patterns of variation at a specific locus, evaluated in the appropriate functional, ecological and/or historical contexts, can reveal the occurrence of adaptive and neutral processes affecting the evolution of proteins (Feder \& Watt, 1992). Although thorough studies of variation at a single locus are rare, they have been very instructive, and calls for more examples are frequent (e.g. Gillespie, 1991, 1994; Feder \& Watt, 1992; Powers et al., 1994).

One locus which is ideal for such a study is alcohol dehydrogenase $(A d h)$ in tiger salamanders, Ambystoma tigrinum. Mitton et al. (1986) reported that $A d h$ contributed significantly to correlations between multilocus heterozygosity and both resting 
and active oxygen consumption in one subspecies of adult (air-breathing) tiger salamanders (Ambystoma tigrinum mavortium), and that significant differences in size existed among $A d h$ genotypes in two natural populations of gilled larvae of another subspecies of tiger salamander (Ambystoma tigrinum nebulosum). Both ecologically and functionally oriented questions can be generated from these results; here ecological questions are addressed relating to the effect of environmental variables on tiger salamander fitness, and whether $A d h$ variation in natural populations of tiger salamanders is maintained by adaptive and/or nonadaptive evolutionary processes. Only gilled salamanders were studied because they are restricted to aquatic habitats, are easier to locate, and occur in higher population densities than adults. Pond oxygen level was chosen as an environmental variable likely to be relevant to gilled salamander growth and survival (Branch \& Taylor, 1977) and to Adh genotype frequency (Mitton et al., 1986). In addition, populations that lived in high-altitude ephemeral ponds in western Colorado were studied, as organisms living in extreme environments are more likely to show pronounced effects of evolutionary processes (Gillespie, 1991; Hoffmann \& Parsons, 1991).

The first objective of the study was to determine whether environmental oxygen levels affected components of fitness in tiger salamanders. To this end, body mass and metamorphic class were measured as components of fitness relating to size, growth and the ability to reach reproductive adulthood, and dissolved oxygen was measured in the ponds (both natural and laboratory) in which the salamanders lived. The second objective was to measure correlations between $A d h$ genotype and environmental oxygen levels, and between $A d h$ genotype and components of fitness (survival, size and metamorphosis), to determine which evolutionary processes, and under what environmental conditions, might affect $A d h$ genotype frequency. Under a given set of environmental conditions, the existence of strong correlations would suggest that selection is occurring for $A d h$ or for a locus to which $A d h$ is linked (Arnold, 1983; Endler, 1986), whereas the absence of correlations would be consistent with the occurrence of drift.

\section{Materials and methods}

\section{Sampling natural populations}

Gilled Ambystoma tigrinum nebulosum were collected from the following widely dispersed loca- tions in western Colorado: Tuttle Pond, elevation $2910 \mathrm{~m}, 1.6 \mathrm{~km}$ south-east of Gothic; Kebler Pass Pond, elevation $2440 \mathrm{~m}, 40 \mathrm{~km}$ west of Crested Butte; Lost Canyon Pond, elevation 2880 m, 24 km north-east of Gunnison; Rainbow Lake Road Pond $1 \mathrm{R}$, elevation $2835 \mathrm{~m}, 27 \mathrm{~km}$ north-west of Gunnison; Rainbow Lake Road Pond 2L, elevation $2865 \mathrm{~m}, 32 \mathrm{~km}$ north-west of Gunnison; Pond 149, elevation $2610 \mathrm{~m}, 53 \mathrm{~km}$ south-west of Gunnison; Pond 149-22, elevation $2440 \mathrm{~m}, 35 \mathrm{~km}$ south-west of Gunnison; and Deer Lakes Pond, elevation 3065 m, $13 \mathrm{~km}$ east of Slumgullion Pass. Up to 80 salamanders per sample were collected with a seine net and transported to the Rocky Mountain Biological Laboratory in pond water contained in ice chests. The pond water was immediately replaced by fresh cold water, and the animals were stored at $10^{\circ} \mathrm{C}$. Individuals were measured to the nearest millimetre for snout-vent length, weighed to the nearest tenth of a gram for body mass, and tail clipped to provide an electrophoretic sample. Salamanders were usually too small to be marked with toe clips, and the tail clip generally was not distinguishable from natural damage to the tails of many salamanders. Each individual was classified into a metamorphic group, derived from the classification scheme proposed for Ambystoma tigrinum by Norman (1985). Norman's stage I was designated fully gilled, stage II to stage IV were designated near adult, stage VI was designated very near adult, and stage VII was designated as adult. Salamanders were returned to their native pond within $72 \mathrm{~h}$ of the time of collection.

Water oxygen levels and temperatures in the ponds were measured using a YSI 51B oxygen meter and probe. Daytime oxygen maxima were determined to occur in early to mid-afternoon. At least three measures of dissolved oxygen and water temperature were taken before seine netting on each sampling occasion, and three more were taken when the animals were returned after electrophoresis. Dissolved oxygen levels, recorded in mg of oxygen per litre of water, were converted to percentage air saturation values, corrected for temperature and elevation, following Hutchinson (1957) and Wetzel \& Likens (1991).

\section{Artificial ponds}

Artificial ponds in the laboratory were established in 55 -gallon dark plastic garbage cans to allow the study of metamorphosis under controlled conditions. Normoxic ponds were bubbled with a mixture of nitrogen and oxygen to yield 80 per cent saturation at $20^{\circ} \mathrm{C}$; hypoxic ponds were bubbled with a mixture 
of oxygen and nitrogen to yield 20 per cent saturation at $20^{\circ} \mathrm{C}$. An oscillating fan blew fresh air across the surface of both hypoxic and normoxic ponds, and oxygen levels were routinely measured using a YSI 51B meter and probe. Lighting conditions were artificial, with day length set to $14 \mathrm{~h}$, and the salamanders were fed trout chow ad libitum. Animals used in artificial ponds were allowed to acclimatize to laboratory conditions for 2 weeks before being placed in the selected oxygen environment for a period of 3 weeks.

\section{Electrophoresis}

Tail muscle was homogenized in three volumes of an ice-cold Tris grinding buffer (Watt, 1977) and centrifuged for $5 \mathrm{~min}$ in an Eppendorf microcentrifuge at $4^{\circ} \mathrm{C}$ to pellet out cellular debris. Electrophoresis of homogenates was performed using discontinuous polyacrylamide slab gels following Watt (1977). Gels were visualized using $1.5 \mathrm{~mL}$ of 95 per cent ethanol, $10 \mathrm{mg}$ of NAD, $4 \mathrm{mg}$ of MTT and $2 \mathrm{mg}$ of phenazine ethosulphate in $50 \mathrm{~mL}$ of stain buffer (Watt, 1977).

\section{Statistics}

Nonparametric correlation analyses were conducted using sPSs-PC on an IBM-compatible personal computer, following Sokal \& Rohlf (1981) and Rohlf \& Sokal (1981). Binomial tests of proportions were calculated to test for statistical significance between sample frequencies (Larsen \& Marx, 1981). Goldstein's (1964) $x^{*}$ nomenclature is used in tables and text to identify the binomial statistic (Watt et al., 1986). The $G$-statistic was calculated from contingency tables to test for differences in relative frequencies of all three genotypes between different samples from the same pond; for a discussion of why the 'traditional' $\chi^{2}$-test was not used, see Sokal \& Rohlf (1981).

\section{Results}

\section{Environmental stress}

Many of the ponds in western Colorado are ephemeral, drying in late summer or freezing solid in winter. Six of the eight ponds examined here dried before 1 September in at least one of the four years studied; several of these dried every year in the late summer. Gilled salamanders remaining in the pond at the time of drying died from desiccation, and hence pond drying is a severe stress, influencing life history variation and components of fitness.

An effect of low water oxygen slowing metamorphosis was indirectly observed in the field and measured directly in the laboratory. Salamanders were never observed metamorphosing in hypoxic natural ponds (daily high oxygen saturation less than 60 per cent). During a 3-week period in the laboratory, 23.7 per cent of 38 salamanders living in hypoxic artificial ponds (oxygen saturation of 20 per cent) metamorphosed, compared with 50.0 per cent of 40 salamanders in normoxic artificial ponds (oxygen saturation of 80 per cent); this difference was statistically significant $\left(x^{*}=2.4, P=0.01\right)$.

\section{Pond oxygen and Adh relationships}

Adh genotype frequency was plotted against the daily maximum oxygen saturation of each pond from which salamanders were collected during the first year in which that pond was sampled. The Adh-SS genotype was significantly positively correlated with pond oxygen levels (Fig. 1; Spearman's $r h o=0.738$, $P=0.037) ; A d h-S S$ thus occurred in low frequency in ponds with low levels of oxygen. The correlation between $A d h-F F$ frequency and pond oxygen was negative but not significant (Fig. 2; Spearman's rho $=-0.667, P=0.14$ ). This value of $P$ was doubled from that determined in the correlation table to account for the nonindependence of the genotype frequencies using a sequential Bonferroni correction (Milliken \& Johnson, 1984). The correlation between $A d h-S F$ frequency and pond oxygen (Fig. 3; Spearman's rho $=-0.31$ ) cannot be tested statistically using a sequential Bonferroni correction. However, the value of rho and inspection of the figure suggest that $A d h-S F$ was unrelated to daily

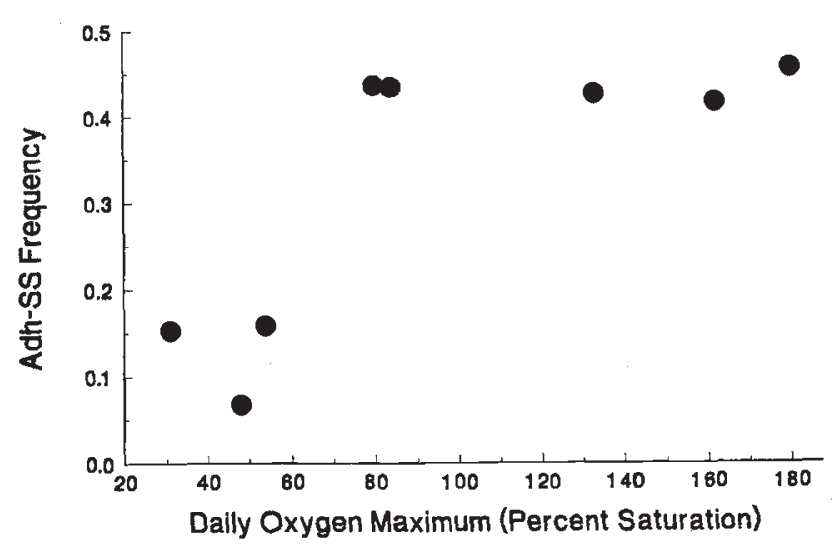

Fig. 1 Frequency of $A d h-S S$ in tiger salamanders as a function of daily oxygen maxima, expressed as percentage saturation. Spearman's $r h o=0.738, P=0.037$. 


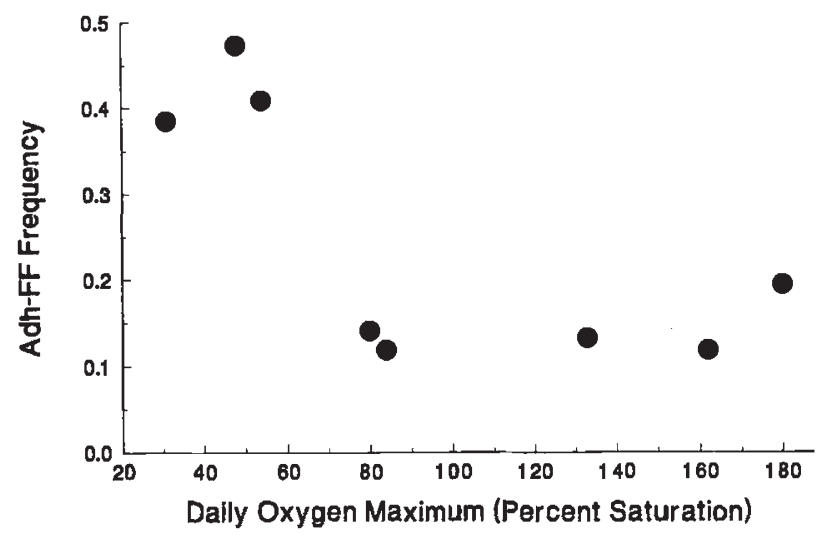

Fig. 2 Frequency of $A d h-F F$ in tiger salamanders as a function of daily oxygen maxima, expressed as percentage saturation. Spearman's $r h o=-0.667, P=0.14$, with $P$ corrected for nonindependence of frequencies using a Bonferroni correction (Milliken \& Johnson, 1984).

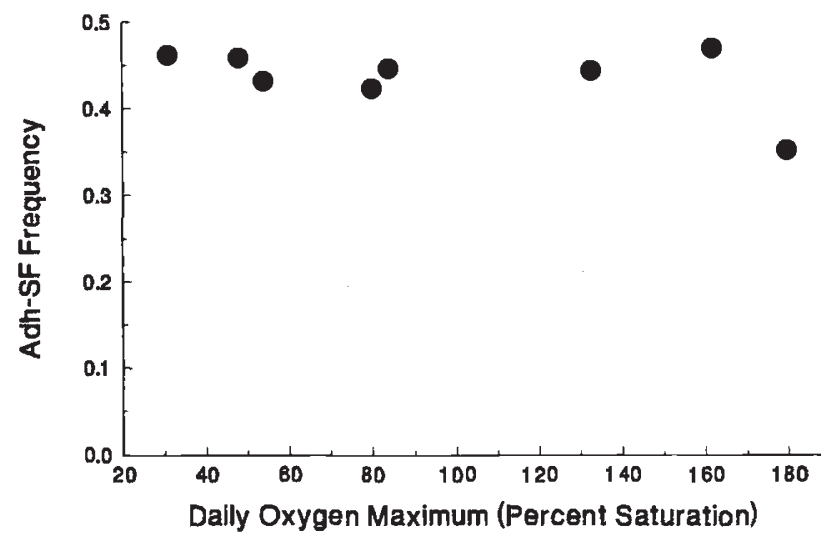

Fig. 3 Frequency of $A d h-S F$ in tiger salamanders as a function of daily oxygen maxima, expressed as percentage saturation. Spearman's rho $=-0.309$. The significance of this correlation cannot be tested because of the nonindependence of the genotype frequencies (Milliken \& Johnson, 1984).

Table $1 A d h$ genotype frequencies and sample sizes of tiger salamanders from a hypoxic pond and a supersaturated pond, each of which was sampled three times in two different years. The $G$-statistic, and its associated value of $P$, calculated from contingency table analysis comparing the first and last sample from each pond in each season, are also presented

\begin{tabular}{|c|c|c|c|c|c|c|}
\hline Pond/date & $S S$ & $S F$ & $F F$ & $n$ & $G_{2}$ & $P$ \\
\hline \multicolumn{7}{|c|}{ Lost canyon (hypoxic) } \\
\hline 7 July 1988 & 0.324 & 0.567 & 0.108 & 37 & & \\
\hline 8 Aug 1988 & 0.167 & 0.417 & 0.417 & 72 & & \\
\hline 1 Oct 1988 & 0.164 & 0.466 & 0.370 & 73 & 10.23 & $<0.01$ \\
\hline 15 July 1991 & 0.117 & 0.338 & 0.545 & 77 & & \\
\hline 14 Aug 1991 & 0.039 & 0.455 & 0.506 & 77 & & \\
\hline 30 Aug 1991 & 0.143 & 0.441 & 0.376 & 74 & 3.60 & $>0.25$ \\
\hline \multicolumn{7}{|c|}{ Pond 149 (supersaturated) } \\
\hline 25 July 1990 & 0.250 & 0.325 & 0.425 & 80 & & \\
\hline 13 Aug 1990 & 0.291 & 0.405 & 0.304 & 79 & & \\
\hline 28 Aug 1990 & 0.456 & 0.351 & 0.193 & 57 & 10.02 & $<0.01$ \\
\hline 9 July 1991 & 0.286 & 0.428 & 0.299 & 77 & & \\
\hline 7 Aug 1991 & 0.220 & 0.500 & 0.280 & 100 & & \\
\hline 3 Sep 1991 & 0.200 & 0.510 & 0.286 & 35 & 1.11 & $>0.50$ \\
\hline
\end{tabular}

oxygen maxima. Thus, Adh-SS was found in low frequency in hypoxic ponds, $A d h-F F$ tended to be found in low frequency in supersaturated ponds (although not significantly so) and $A d h-S F$ frequency was unrelated to pond oxygen levels.

Two ponds, one hypoxic and one supersaturated, were each sampled three times during two different seasons (Table 1). Differences in $A d h$ genotype frequency between the first and third sample in each pond in each year were tested for statistical significance using a $G$-test of contingency table analysis (Sokal \& Rohlf, 1981). In the hypoxic pond in 1988, a significant change in genotype frequencies occurred over the season, with the relative frequency of $A d h-S S$ dropping and the relative frequency of $A d h-F F$ increasing. This change was consistent with the low frequency of $A d h-S S$ in hypoxic ponds shown in Fig. 1. In the same pond in 1991, no significant changes in relative frequencies of $A d h$ occurred from the first to the third sampling date. Differences between the second sampling date and the first and third sampling dates were also statistically tested, with the value of $P$ modified by a Bonferroni correction (Milliken \& Johnson, 1984); 
in neither case were the results statistically significant (date 1 vs. date $2, G_{2}=4.58, P>0.21$; date 2 vs. date $3, G_{2}=6.29, P>0.12$ ). In the supersaturated pond in 1990, a significant change in relative $A d h$ genotype frequency occurred in a direction consistent with the low frequency of $A d h-F F$ in supersaturated ponds shown in Fig. 2. In the same supersaturated pond in 1991, no significant changes in relative frequency of $A d h$ occurred across the season.

\section{Body mass, metamorphosis and Adh}

Body mass was measured for all individuals collected and analysed by genotype; 23 samples from eight different ponds were collected over 4 years. On only two occasions did significant differences occur among genotypes in body mass (with $A d h$-SS being heaviest and $A d h-F F$ lightest). Both of these occurred in the same pond at different times in the same season, so the two results are not independent. In addition, no trends existed for any of the genotypes to be larger across all samples. Thus, no consistent differences in body mass among $A d h$ genotypes were measured.

To test whether differences existed among $A d h$ genotypes in time to metamorphosis, a drift fence and pitfall traps were placed around Pond 149 in the summer of 1991 . The population was sampled immediately before establishing the fence; individuals that later metamorphosed and were captured in traps were also genotyped. The genotype frequency distributions of the population as a whole and of the fraction that metamorphosed were highly significantly different $\left(G_{2}=12.88, P<0.005\right.$; Fig. 4), with $A d h-S F$ and $A d h-S S$ in higher frequency, and $A d h-F F$ in lower frequency, among metamorphic adults than in the population as a whole. Pond 149 was supersaturated with oxygen; thus, the low rate of metamorphosis among the $A d h-F F$ individuals was consistent with the generally low frequency of $A d h-F F$ genotypes in populations in supersaturated ponds and with the significant drop in $A d h-F F$ frequency across the season measured in a supersaturated pond.

Because metamorphosis was not observed in hypoxic natural ponds, artificial ponds were established in the laboratory on two separate occasions in order to study metamorphosis under hypoxia. Figure 5 shows $A d h$ genotype frequency distributions for emerging adults in normoxic and hypoxic water for both laboratory trials. Animals used in trial A were collected from a normoxic pond; animals used in trial B were collected from a hypoxic pond. In both

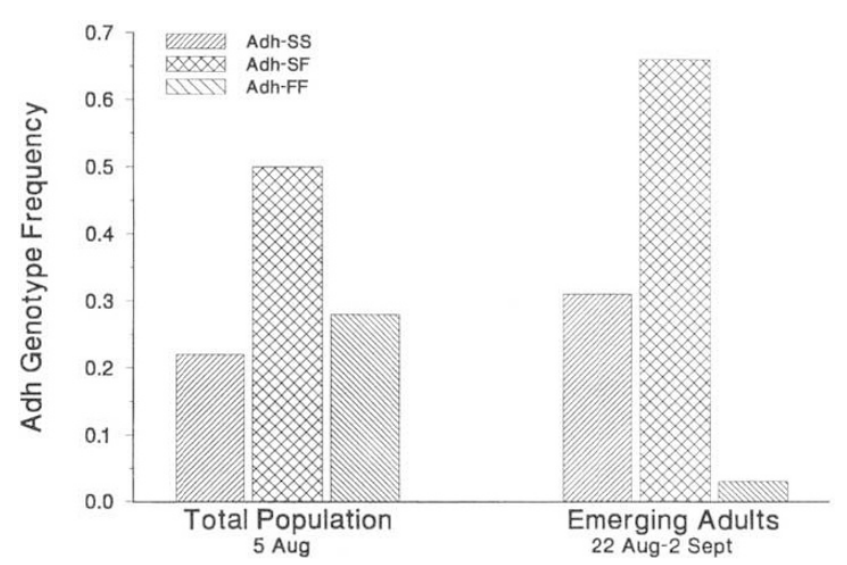

Fig. $4 A d h$ genotype distributions in the total population of tiger salamanders $(n=100)$ vs. emerging adults $(n=35)$ in Pond 149 in 1991. The genotype distributions in the two samples are significantly different $\left(G_{2}=12.88\right.$, $P<0.005)$.

trials, the relative frequencies of $A d h$ genotypes among adults emerging from normoxic water appeared similar to the relative frequencies of all the animals in the normoxic water. However, among emerging adults in hypoxic water, the relative frequencies looked different from those in the population as a whole, with $A d h-S F$ apparently being at a higher frequency. In order to test these apparent differences statistically and to try to determine the cause of the relative changes in genotype frequency, the proportion of each genotype metamorphosing in normoxic vs. hypoxic water was compared (Table 2). Because each genotype was considered singly and relative frequencies were not used, the results for each genotype were statistically independent.

A one-tailed test of significance was applied to the $A d h-S S$ data because of $a$ priori expectations, based on the field data presented above, that $A d h-S S$ performed poorly in hypoxic water. In trial $\mathrm{A}$, the Adh-SS homozygote showed a marginally nonsignificant difference in proportions metamorphosed in normoxic vs. hypoxic water, with lower proportions metamorphosing in the hypoxic water $\left(x^{*}=1.60\right.$, $P=0.055)$. In trial $\mathrm{B}$, this pattern was repeated, with the difference now being statistically significant $\left(x^{*}=1.83, P=0.034\right)$. In trial A, $A d h-F F$ showed a nonsignificant difference in proportions metamorphosing in normoxic vs. hypoxic water $\left(x^{*}=1.56\right.$, $P=0.119$ ), with the lower proportion of metamorphs occurring in hypoxic water. In trial $\mathrm{B}$, the same trend occurred, but with the differences being highly significant $\left(x^{*}=3.23, P=0.001\right)$. The lack of correspondence in statistical significance between trials may have been caused by the fact that trial A 
animals were collected from a normoxic pond, whereas the animals used in trial B were collected from a hypoxic pond.

However, in neither trial did differences exist in the proportion of $A d h-S F$ heterozygotes metamorphosing between hypoxic and normoxic water. The $A d h-S F$ genotype metamorphosed equally well in both oxygen environments, whereas in trial B the Adh homozygotes metamorphosed more slowly in the hypoxic water. Thus, the apparent differences in relative frequencies (Fig. 5) among genotypes in their ability to metamorphose in hypoxic water were caused by homozygotes performing poorly under hypoxia relative to normoxia, whereas the heterozygote was unaffected by oxygen conditions (Table 2).

\section{Discussion}

In these ephemeral ponds, tiger salamanders must hatch from eggs, grow as gilled larvae and metamorphose into terrestrial adults during a single summer before the ponds dry. Individuals that remain aquatic are not likely to survive to the following spring, because the ponds either evaporate or freeze. In addition, both field observations and laboratory
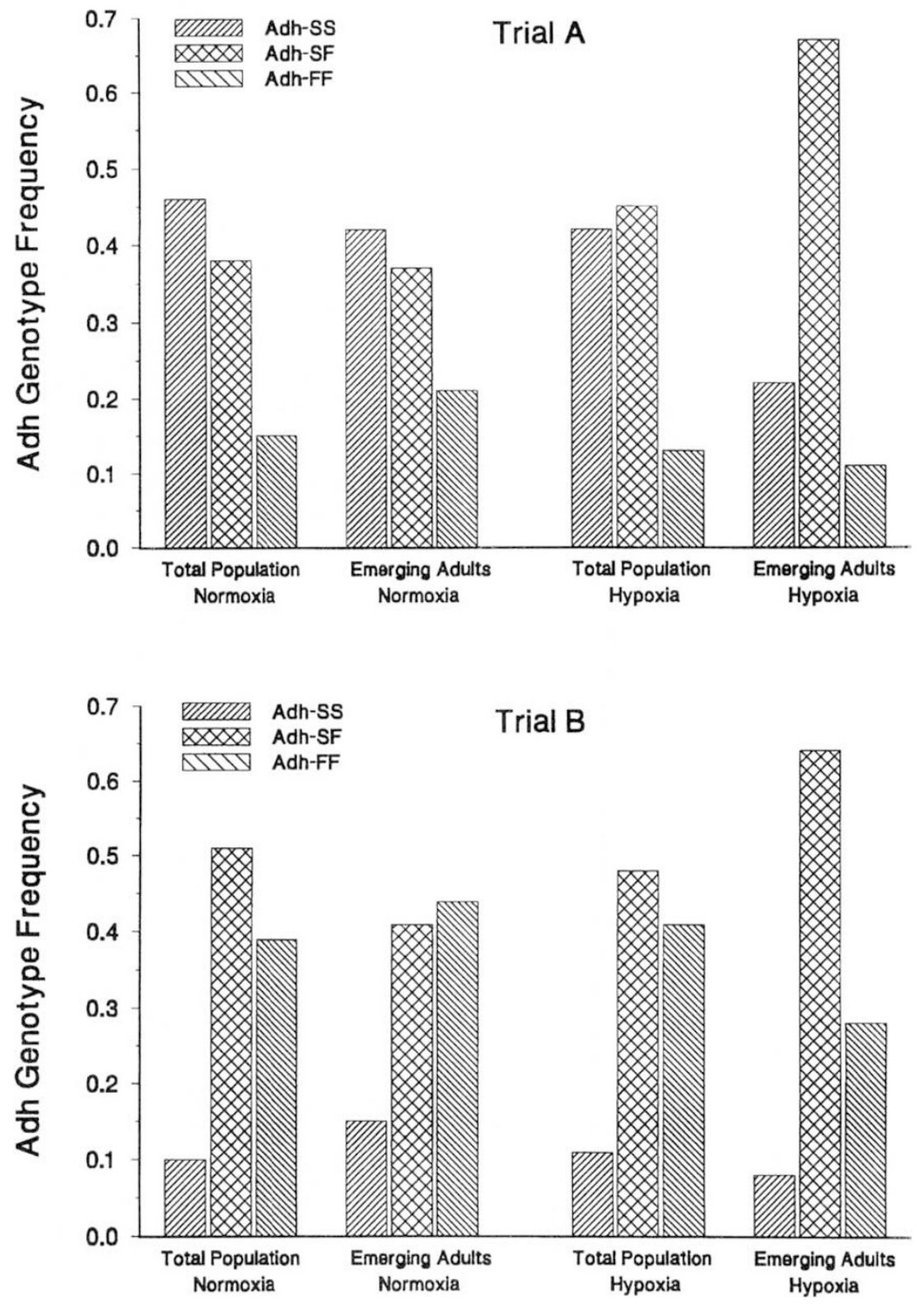

Fig. 5 Adh genotype distributions in the total population and emerging adult tiger salamanders in normoxic and hypoxic artificial ponds in two separate laboratory trials. 
Table 2 Proportion and (sample size) of each genotype of tiger salamanders metamorphosing into adults in artificial ponds in the laboratory

\begin{tabular}{|c|c|c|c|c|c|c|c|c|}
\hline \multirow[b]{2}{*}{ Genotype } & \multicolumn{4}{|c|}{ Laboratory trial A } & \multicolumn{4}{|c|}{ Laboratory trial B } \\
\hline & Normoxic & Hypoxic & $x^{*}$ & $P$ & Normoxic & Hypoxic & $x^{*}$ & $P$ \\
\hline$A d h-S S \dagger$ & $0.444(18)$ & $0.200(10)$ & 1.60 & 0.055 & $0.555(9)$ & $0.143(14)$ & 1.83 & 0.034 \\
\hline$A d h-S F$ & $0.533(15)$ & $0.375(16)$ & 0.52 & 0.603 & $0.295(44)$ & $0.364(44)$ & 0.68 & 0.497 \\
\hline$A d h-F F$ & $0.667(6)$ & $0.200(5)$ & 1.56 & 0.119 & $0.700(20)$ & $0.233(30)$ & 3.23 & 0.001 \\
\hline
\end{tabular}

$x^{*}$ represents the binomial test of proprotions statistic.

†One-tailed $P$-values were used for $A d h$-SS because of the a priori expectation, based on the field data, that $A d h$-SS performs poorly in hypoxic water (see text).

experiments demonstrated that low water oxygen slows salamanders' time to metamorphosis. Thus, strong selection occurs against tiger salamanders that do not metamorphose rapidly, and the intensity of this selection is dependent on water oxygen.

Variation at the $A d h$ locus is correlated with pond oxygen levels. The positive correlation between $A d h-S S$ and pond oxygen may be caused by the same factor affecting the results in Table 1; the drop in $A d h$-SS frequency in the hypoxic pond in 1988 suggests that $A d h-S S$ individuals might experience high mortality under these conditions. Mortality among gilled Ambystoma is known to be high in the early season, when this decrease in $A d h-S S$ frequency occurred (Anderson et al., 1971; Peterson et al., 1991). Another explanation is that $A d h-S S$ individuals were metamorphosing and leaving the pond; however, no advanced metamorphic stage animals were observed in this pond during 1988. In addition, laboratory experiments demonstrated that $A d h-S S$ individuals metamorphose more slowly than expected in hypoxic water (Table 2). A third explanation is that $A d h$-SS individuals hatched sooner than $A d h-F F$ individuals, and that this caused a late season increase in $A d h-F F$. $L d h$ genotype is correlated with hatch rate in killifish (Powers et al., 1994); such a relationship between $A d h$ genotype and hatch rate in salamanders can be examined in the future.

Similarly, the nonsignificant trend for $A d h-F F$ to be negatively correlated with pond oxygen may be at least partly explained by the results in Table 1 . The significant change in genotype frequencies in the supersaturated pond in 1990 may be caused by higher mortality among $A d h-F F$ individuals. A higher rate of metamorphosis causing the change in genotype frequency is possible but not likely, because salamanders in advanced metamorphic stages were only just appearing during the third sample and comprised less than 9 per cent of the population. In addition, data from the same pond in 1991 demonstrated a severe lack of $A d h-F F$ among metamorphic animals leaving the pond. Interestingly, the 3 September 1991 sample from Pond 149 (Table 1) was taken after collection of animals in the pitfall traps from the same pond (Fig. 4). The lack of an increase in $A d h-F F$ frequency in the animals remaining in the pond, and the very low numbers of $A d h-F F$ individuals metamorphosing and exiting the pond, suggests that $A d h-F F$ individuals were indeed experiencing high mortality. High mortality rates among metamorphosing Ambystoma have been reported elsewhere (Peterson et al., 1991).

Finally, the shape of the curves in Figs 1 and 2 suggests that 60 per cent oxygen saturation may be a threshold above which genotype frequencies do not change much. Additional field and laboratory studies may be conducted to investigate this possibility and to measure the effects of 40 per cent to 80 per cent oxygen saturation on individual survival and metamorphosis.

Variation at the $A d h$ locus is also associated with time to metamorphosis. Individuals of the $A d h-S S$ genotype metamorphose more slowly in hypoxic water and so are at a disadvantage in low-oxygen ponds. $A d h-F F$ individuals metamorphose more slowly in both hypoxic and supersaturated water and so are at a disadvantage in both high- and low-oxygen ponds. In contrast, $A d h-S F$ individuals metamorphose equally well in normoxic, hypoxic and supersaturated water. Because $A d h$ heterozygotes metamorphose in relatively higher frequencies than both homozygotes in extreme oxygen environments, $A d h-S F$ individuals are likely to comprise a larger proportion of breeding adults. This over-representation of $A d h$ heterozygotes among breeders is sufficient to explain the maintenance of the $A d h$ polymorphism, assuming no selection against 
$A d h-S F$ individuals in survival or reproduction in postmetamorphic salamanders.

Under extreme oxygen conditions, the cause of selection of $A d h$ through differential metamorphosis and perhaps differential survival may be unrelated to the Adh locus itself. Adh might be in linkage disequilibrium with a locus for which selection actually occurs, in which case selection for the linked locus could result in selection of $A d h$ (Endler, 1986; Gillespie, 1991). On the other hand, the cause of the reported selection of $A d h$ could be selection for $A d h$. One way this can occur is by selection for catalytic differences among allozymes. For example, selection for the $L d h$ locus in killifish occurred because of catalytic differences among $L d h$ allozymes (Powers et al., 1994); a similar result was reported for the Pgi locus in sulphur butterflies (Watt, 1991).

Catalytic differences among $A d h$ allozymes in tiger salamanders have been measured (P. A. Carter et al., in preparation). The $A d h-S F$ heterozygote allozyme has a higher $k_{\text {cat }} / k_{\mathrm{m}}$ ratio in both reaction directions than does the $A d h-F F$ homozygote, and the $A d h-S S$ has a higher $k_{\text {cat }} / k_{\mathrm{m}}$ ratio in one reaction direction than does the $A d h-F F$. Differences also exist among genotypes in the number of ATP bound per haemoglobin, which affects the ability of the haemoglobin to transport oxygen. The existence of these functional differences among $A d h$ allozymes supports the hypothesis that the selection of $A d h$ reported here is selection for $A d h$ itself, and that this selection is caused at least in part by catalytic differences among the allozymes.

Whatever the cause of the selection of $A d h$, the $A d h$ polymorphism in tiger salamanders is maintained by the high performance of $A d h-S F$ individuals relative to the performance of $A d h-S S$ and $A d h-F F$ individuals in extreme oxygen environments. In populations living in chronically normoxic ponds or in non-ephemeral ponds in which rapid metamorphosis is not crucial for survival, $A d h$ genotype frequencies might only be affected by nonselective evolutionary processes (e.g. drift). These results demonstrate the complexity of interpreting the evolutionary significance of variation at specific loci and provide an example in which such variation is affected by natural selection under one set of environmental conditions.

\section{Acknowledgements}

I thank William Barr, Erin Fernandez, Tamara Fraizer, Paul Groff, Julie Hunley, Susan Allen Lohr and Eric Subin for help in collecting salamanders;
Joan Milam for help in establishing drift fences and digging pitfall traps; Ted Garland, Steve Hand, Jeff Mitton, Allen Moore, Barney Rees, Dirk Van Vuren and Ward Watt for helpful discussions on this research; and Jeff Mitton and two anonymous reviewers for comments on this manuscript. I especially thank Ward Watt for his generosity in allowing me to use his laboratory space at RMBL. This research was funded by the University of Colorado Foundation, the University of Colorado Lichty fund and the Rocky Mountain Biological Laboratory's Snyder and AMAX scholarships.

\section{References}

ANDERSON, J. D., HASSINGER, D. D. AND DALRYMPLE, G. H. 1971. Natural mortality of eggs and larvae of Ambystoma t. tigrinum. Ecology, 52, 1107-1112.

ARNOLD, s. J. 1983. Morphology, performance and fitness. Am. Zool., 23, 347-361.

BRANCH, L. C. AND TAYLOR, D. H. 1977. Physiological and behavioural responses of larval spotted salamanders (Ambystoma maculatum) to various concentrations of oxygen. Comp. Biochem. Physiol., 58 A, 269-274.

FEDER, M. E. AND WATT, W. B. 1992. Functional biology of adaptation. In: Berry, R. J., Crawford, T. J. and Hewitt, G. M. (eds) Genes in Ecology, pp. 365-392. Blackwell Scientific Publications, Oxford.

ENDLER, J. A. 1986. Natural Selection in the Wild. Princeton University Press, Princeton, NJ.

GARLAND, T., JR. AND CARTER, P. A. 1994. Evolutionary physiology. Ann. Rev. Physiol., 56, 579-621.

GILlespIE, J. 1991. The Causes of Molecular Evolution. Oxford University Press, Oxford.

GILlespie, J. 1994 Alternatives to the neutral theory. In: Golding, B. (ed.) Non-neutral Evolution, pp. 1-17. Chapman \& Hall, New York.

GOLdSTEIN, A. 1964. Biostatistics. Macmillan, New York.

GRAVES, J. E. AND SOMERO, G. N. 1982. Electrophoretic and functional enzymic evolution in four species of eastern Pacific barracudas from different thermal environments. Evolution, 37, 30-37.

HOCHACHKA, P. W. AND SOMERo, G. N. 1984. Biochemical Adaptation. Princeton University Press, Princeton, NJ.

HOFFMANN, A. A. AND PARSONS, P. A. 1991. Evolutionary Genetics and Environmental Stress. Oxford University Press, Oxford.

HUTCHINSON, G. E. 1957. A Treatise on Limnology, volume I. John Wiley \& Sons, New York.

LARSEN, R. J. AND MARX, M. L, 1981. An Introduction to Mathematical Statistics and its Applications. Prentice Hall Inc., Englewood Cliffs, NJ.

Milliken, G. A. AND JOHnson, D. E. 1984. Analysis of Messy Data. vol. 1: Designed Experiments. Chapman \& Hall, London.

MitTon, J. B., CAREY, C. AND Kocher, T. D. 1986. The relation of enzyme heterozygosity to standard and 
active oxygen consumption and body size of tiger salamanders, Ambystoma tigrinum. Physiol. Zool., 59, 574-582.

NORMAN, M. F. 1985. A practical method for staging metamorphosis in the tiger salamander Ambystoma tigrinum. Anat. Rec., 211, 102-109.

PETERSON, C, L., WILKINSON, R. F., MOLL, D. AND HOLDER, T. 1991. Premetamorphic survival of Ambystoma annulatum. Herpetologica, 47, 96-100.

POWERS, D. A., SMITH, M., GONZALES-VILLASENOR, I., DIMICHELE, L., CRAWFORD, D., BERNARDI, G. AND LAUERMAN, T. 1994. A multidisciplinary approach to the selectionist/neutralist controversy using the model teleost, Fundulus heteroclitus. Oxford Surveys in Evolutionary Biology, 9, 43-108.

ROHLF, F. J., AND SOKAL, R. K. 1981. Statistical Tables. W. H. Freeman \& Co., New York.
SOKAL, R. K. AND ROHLF, F. J. 1981. Biometry, 2nd edn.. W. H. Freeman \& Co., New York.

somero, G. N. 1995. Proteins and temperature. Ann. Rev. Physiol., 57, 43-68.

WATT, w. B. 1977. Adaptation at specific loci. I. Natural selection on phosphoglucose isomerase of Colias butterflies: biochemical and population aspects. Genetics, 87, 177-194.

WATT, w. B. 1991. Biochemistry, physiological ecology, and population genetics - the mechanistic tools of evolutionary biology. Funct. Ecol., 5, 145-154.

WATT, W. B., CARTER, P. A AND DONOHUE, K. 1986. Females' choice of "good genotypes" as mates is promoted by an insect mating system. Science, 233, 1187-1190.

WETZEL, R. G. AND Likens, G. E. 1991. Limnological Analyses, 2nd edn. Springer Verlag, New York. 